\title{
Research on Emotional Product Design based on Subconscious Behavior
}

\author{
Hu Kang, Qiu Jie \\ Wuhan University of Science and Technology
}

\begin{abstract}
In order to study the application and role of subconscious behavior in emotional product design in psychology, this paper analyzes the subconscious behavior of product designers and users from the perspective of design psychology. With the combination of Norman's three-level design and Desmet's emotional design model as well as some successful product cases, emotional resonance can be generated between users and products. This paper discusses design ideas and thinking of emotional products from three aspects: satisfying emotional needs, improving product value and conveying humanistic feelings, so as to help designers improve design.
\end{abstract}

Keywords-Subconsciousness; Product design; Behavior; Emotionalization

\section{INTRODUCTION}

Emotional product design is a design method with potential emotional needs as the main designing principle in the design process. In Delft Design Guide: Design strategies and methods, this design method is based on an emotional design model of Desmet, but this design model has certain limitations. It only pays attention to the emotional effects in the design and ignores the necessary factors and needs in the designing process. However, the subconscious behavior is a direct reflection of the emotions and needs of people [1].

Subconscious behavior in product design directly or indirectly reflects the subtle relationship between people and products. In today's advocacy of humanization design and emotional design, it is not enough to meet the basic needs of users. Product designers should constantly explore and meet the invisible needs of users through design. Research on the relationship and importance of subconscious behavior and emotional product design can help product designers better understand the user's motivations and needs, thus creating a spiritual and emotional resonance with the product.

\section{RESEARCH STATUS OF SUBCONSCIOUS BEHAVIOR IN THE FIELD OF EMOTIONAL PRODUCT DESIGN}

Japanese product designer Naoto Fukasawa proposes the concept of "Without Thought", which aims to transform unconscious behavior into something visible, also known as "intuitive design."

At present, there are not many researches on applying subconscious behavior to emotional product design in China, and more applications are applied to interactive design research By analyzing the user's subconscious behavior habits, the user's cognitive ability is optimized, the learning cost is saved, and the design is closer to the user's expectations. However, no one analyzes and integrates the subconscious behaviors of both users and designers respectively, to make products more emotionally resonate with people.

\section{THE CONCEPT AND CHARACTERISTICS OF SUBCONSCIOUS BEHAVIOR}

\section{A. The concept of subconscious behavior}

The subconsciousness is a special ideology hidden in our brains that is not known by the brain mind. People often analyze it by observing human behavior. Analysis of subconscious behavior is a better way to reflect the world of human consciousness Subconscious behavior is not necessarily owned by adults, it affects us from an early age. Children sometimes can't help but make some movements, they don't know the way but can go home unconsciously. These are the reflections of subconscious influences [2].

\section{B. The characteristics of subconscious behavior}

Through observation and analysis of subconscious behavior, it is found that subconscious behavior has many characteristics such as rapid, spontaneous, emotional, universal and hidden. Subconscious behavior is integrated into life habits and cannot be controlled by people. When encountering a situation, the brain will spontaneously match the operation mode. Instinct response is the most basic level of processing of subconscious behavior, which is rapid and spontaneous. It is closely linked to the movement system. For example, when people are nervous, they will clench their fists and start sweating. This is a physiological subconscious behavior. In addition, subconscious behavior can also be formed by accumulating experience through learning, triggered in the appropriate mode, which is called behavioral response. In this case, people are able to realize our behavior, but often do not know the details. For example, when people do exercises, they do not think about the movements consciously, but the behavioral level has controlled every step of the movements. For example, when people encounter a cylindrical handle, they will choose to rotate, while when they encounter a long handle, they will choose to press down [3]. 


\section{THE APPLICATION OF SUBCONSCIOUS BEHAVIOR IN EMOTIONAL PRODUCT DESIGN}

Product designers in the process of product designing, in addition to the conntrol and analysis of the products function, structure, material and other objective conditions, in the process of product designing Product designers have to employ corresponding design principles to optimize design, also contains some art design elements, which cannot be explained by the design principles and instructions, it mainly relate to designer creation process of people's perception of the unconscious [4].

The production of subconscious behavior is related to the sensory stimulation encountered, the cultural and historical customs of the country or nation, childhood memories, living habits and life scenes and the environment. Product designers should capture these behavioral factors in a timely manner and apply them to product design to meet the invisible needs of users and achieve emotional resonance between customers and products. Emotional product design focuses on the emotional and spiritual needs of users, and adds features such as pleasure and memories to the products while achieving the functions of the products [5].

\section{A. Personal subconscious behavior in emotional product design (designer's perspective)}

Product design can also be regarded as a kind of subconscious behavior under the condition of perceptual thinking. Product designers usually combine their psychological activities, life experience and feelings of beauty to endow products with meanings. However, in this case, it is impossible to explain the design through rational and conscious thinking, and the designed product also has a unique style and is different from other designs. This kind of emotional product resonates with the hidden needs of the user's inner beauty and then creates value.

This personal subconscious behavior is usually associated with childhood memory (Table 1). Freud mentioned in his subconscious doctrine: "The main content of the subconscious is human instinct and its repressive experience, which began in childhood, so the artist's subconscious is often related to childhood memories [6]." For example, the wall hanging CD player designed by Naoto Fukasawa combines his memories of the childhood rope-type light switch, a hanging hemp rope and an electric light, one can pull gently then illuminate the whole house. When customer see this CD player, they will also subconsciously pull it and feel it. This is the product and childhood memories that make the designer and the user emotionally resonate (Figure 1).

\section{B. Collective subconscious behavior in emotional product design (user's perspective)}

Collective subconsciousness refers to the fact that most people in the group have similar psychological activities and life and emotional experiences. This is a common problem that people often encounter in the daily behavior but do not take in the level of consciousness. For instance, when the line is complex, plugs on the wiring board are difficult to distinguish, the cans are not easy to take out from the box, etc. These seemingly small problems that people often encounter in life are not recognized by the user group, but product designers should discover these collective subconscious behaviors that are overlooked, and improve the design through these pain points. This way, it is most easy to resonate with the user's inner feelings by solving a hidden problem in life, and it is also the easiest to meet the user's subconscious needs.

This collective unconscious behavior is often related to people's cultural customs, living environment and living habits (Table 1). For example, the Western dish set designed by Chinese architect Zhang Yonghe (Fig. 2) incorporates the shape of the gourd into the design of Western-style tableware. Farmers in northern China often dry the gourd and cut it in half to scoop water or wash rice. In Chinese culture, the gourd also has the meaning of prosperity and auspiciousness. Therefore, the gourd-shaped tableware will make the Chinese people emotionally resonate, and reinterpret this simple dish with Chinese culture and customs, and let the user rethink the meaning of the family. The lamp with a disc designed by Naoto Fukasawa (Fig. 3), combining the disc and the table lamp. People can turn on the table lamp when put in things, or take out the things then turn off the desk lamp, which not only solves the problem of reminding users to store or take away keys and watches when they go out and go home, but also adds a warm atmosphere to the living environment of the home. It seems that people and desk lamps have emotional communication. For another example, the design of the creative faucet set (Fig. 4) not only satisfies the needs of most young people who are afraid of the bacteria in the cup and directly scoop up water with both hands from the faucet to gargle, but also adds interest to the faucet.

TABLE I.

SUBCONSCIOUS BEHAVIOR CLASSIFICATION TABLE

\begin{tabular}{c|c|c}
\hline & Personal subconscious behavior & Collective subconscious behavior \\
\hline Research object & product designer & user \\
\hline Influencing factor & Childhood memory, etc. & $\begin{array}{c}\text { Cultural customers, living environment, } \\
\text { living habits, etc. }\end{array}$ \\
\hline
\end{tabular}




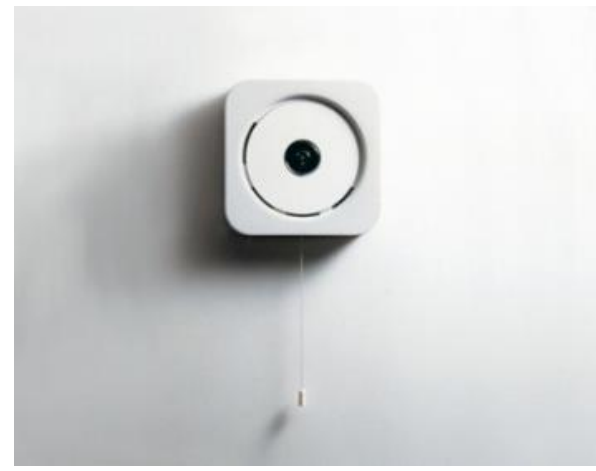

Fig. 1 CD player

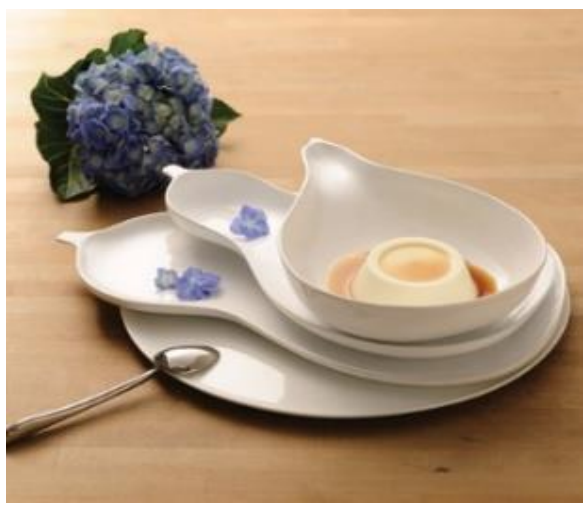

Fig. 2 Western dish set

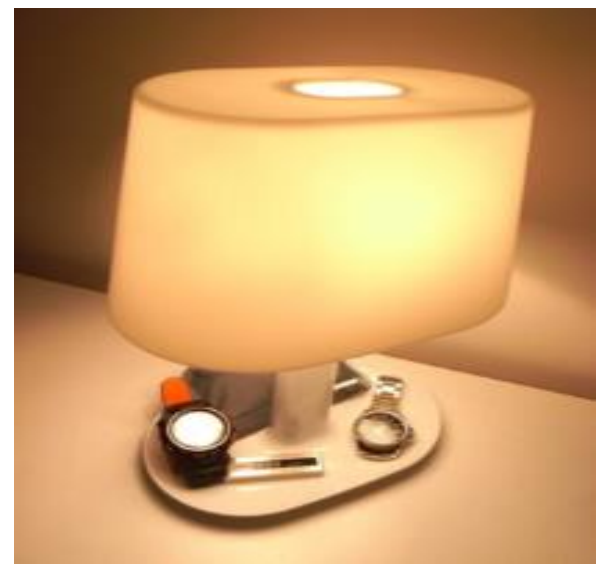

Fig. 3 Lamp with disc

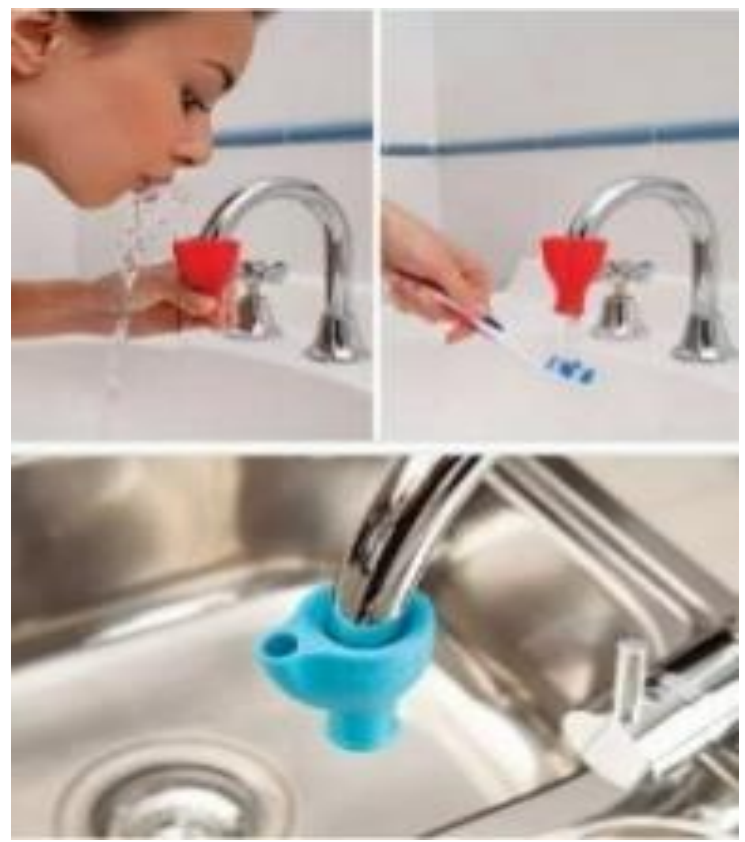

Fig. 4 Creative faucet set

\section{THE EFFECT OF SUBCONSCIOUS BEHAVIOR IN EMOTIONAL PRODUCT DESIGN}

\section{A. Meet emotional needs}

Donald A Norman divides emotional design into visceral design, behavioural design, and reflective design, so that emotional factors are integrated into product design and user experience, to establish a long-lasting emotional bond between the product and the user. Emotional product design based on subconscious behavior can integrate three layers of emotional design to enhance the user's emotional experience while satisfying the user's emotional needs. People and products reach deep emotional resonance (Figure 5). For example, CocaCola's "Sharing Can" limited-edition, the Coke can (Figure 6) can be gently split into two and shared with another person. This creative design improves sharing this subconscious behavior to the emotional level, what shared is not only cola, but also happiness and beautiful memories. In the interactive experience of sharing cola, users and products can generate emotional resonance and give people some enlightenment. 


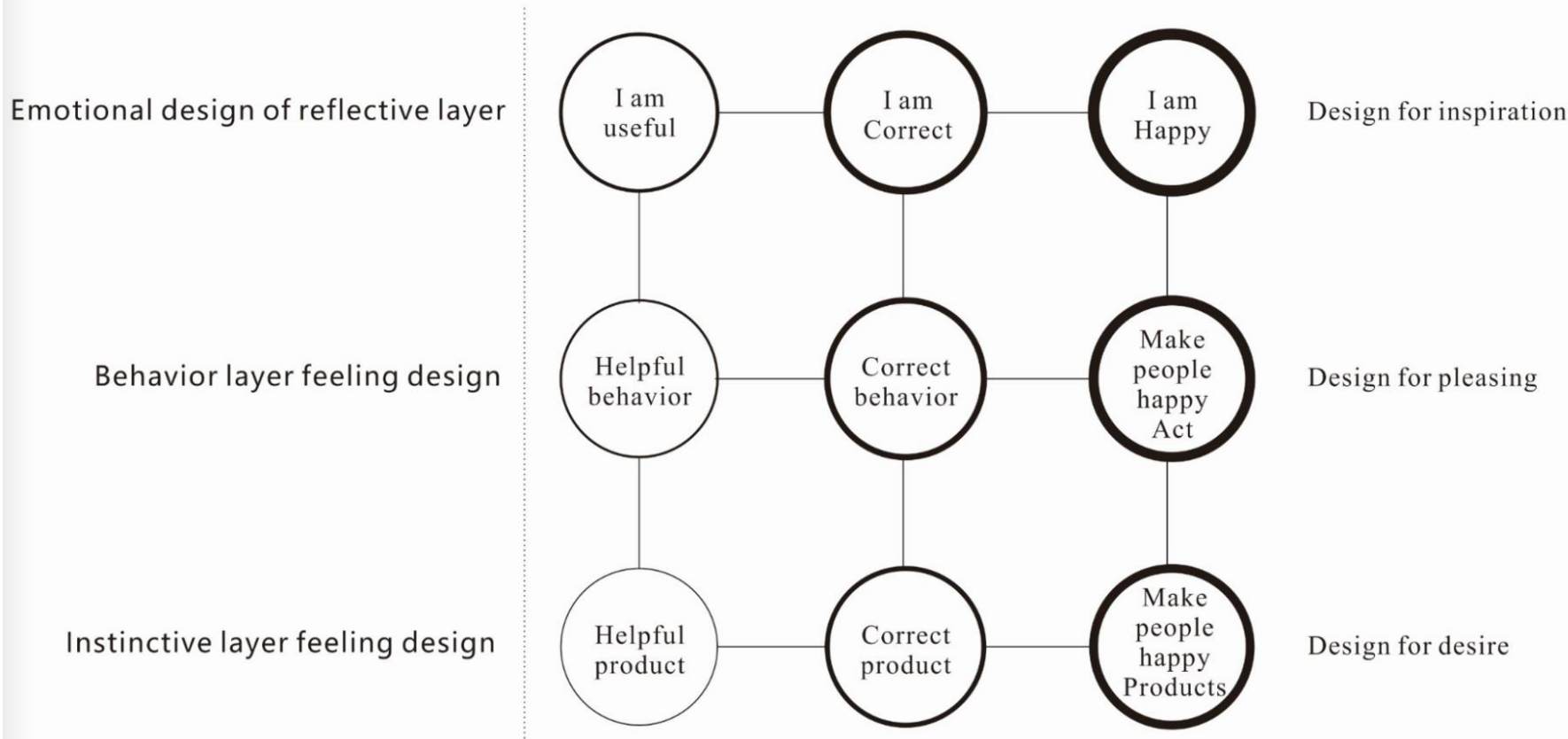

Fig. 5 Three levels of emotional design factors and Desmet's Design for Emotion

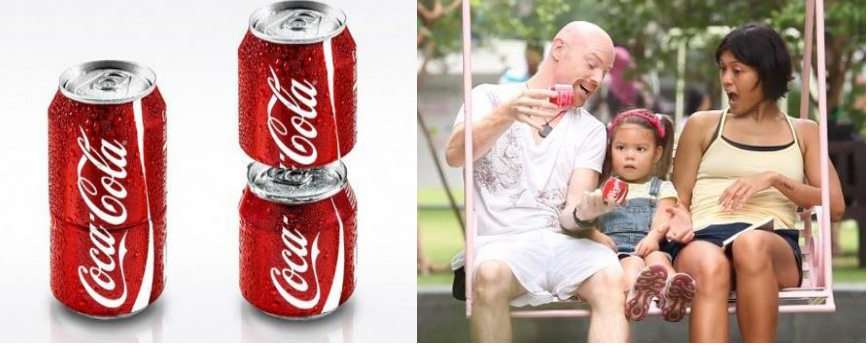

Fig. 6 "Sharing Can" Limited-edition Cola Can

\section{B. Enhance product value}

Product designers can integrate art, culture, technology and other elements into emotional product design through their own life experience and cultural cultivation as well as observation and research on the user's subconscious behavior so as to enhance the added value of the product. For example, the "Juicy Salif" designed by Philippe Starck (Fig. 7) is strange and imaginative. In addition to the function of pressing lemon juice, it can also be used to show off with friends, contrasts the atmosphere and meet the subconscious needs of user's, at the same time its unique shape is enough to be used as an art collection. The 55 degree cup designed by LKK's Jia Wei is also an example of creating added value for the product (Figure 8). The product is originated from his daughter's experience of scalding, he integrates technology and father's love into the design of the cup, so that the user not only experienced convenience of the technology cup also feels the resonance of love and being loved.

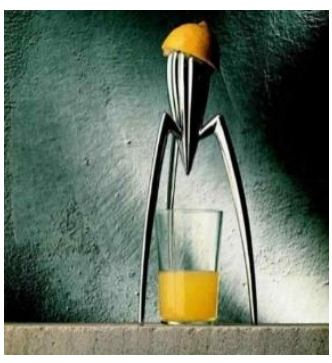

Fig. 7 "Juicy Salif";

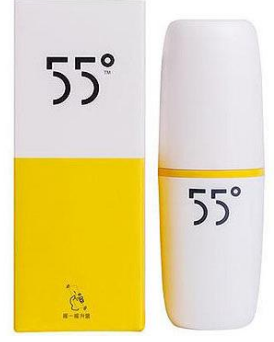

Fig. 855 degree cup

\section{Communicate human feelings}

The humanistic feelings mentioned here include humanistic care and feelings.

Most of the subconscious behaviors in daily life, whether physical or habitual, are difficult to control. Therefore, product designers should pay more attention to this part of the population, especially the elderly, the disabled, patients, etc., in the emotional product design to increase the good user experience, so that users even have a caring experience. For example, the designer's dish washing pad (Figure 9). After washing the dishes in the kitchen for a long time, the waist will obviously be sore, especially the elderly, the subconscious activity is always looking for a place to rely on. This design allows the waist muscles to relax, and the user has a caring emotional resonance.

If an emotional product wants to express emotions and touch the user's inner feelings, it is necessary to interpret the feelings of the products and make the products sensible. Affection is usually based on feelings and able to create a noble, moving mood or sentiment. Product designers should integrate their own feelings into products, degign good products to express their idea, enhance culture and taste of products, and 
impress users while satisfying users' desire to realization of self-worth and improvement of social status. For instance, Tanwai Zhangshengguli (Figure 10), the traditional and heavy Chinese culture are integrated into the product packaging design. The simple and literary art conveys the craftsmanship and heaven worshiping, convesation and love. The brand express that they sell not the agricultural products, but also the Chinese culture.

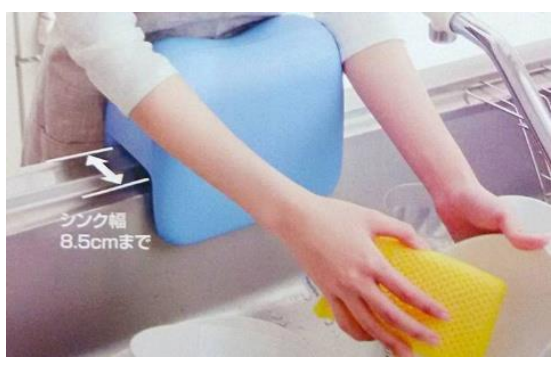

Fig. 9 Dish Washing Pad

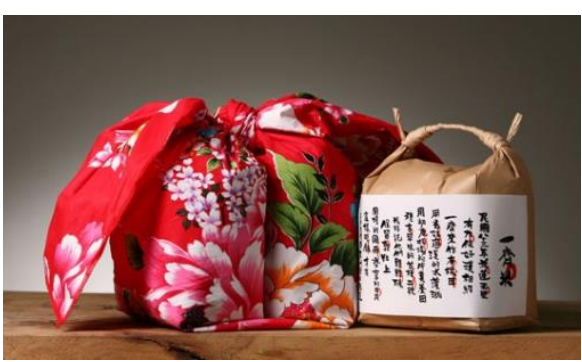

Fig. 10 Zhangshengugli

\section{CONCLUSION}

In the context of the rapid development of industrial design at this stage, an excellent product design wants to be unanimously recognized by users, in addition to meet the basic needs of users, he also has to resonate internally and emotionally with users, and this resonance comes from the user's subconscious behavior. The research on the design of emotional products based on the theory of subconscious behavior provides convenience for more accurate satisfaction of the emotional and spiritual needs of users. Based on the application analysis of subconscious behavior in emotional product design, this paper separately considers the product designer and user experience to obtain the design method and inspiration in the emotional product design, and then perfect the design.

\section{REFERENCES}

[1] Industrial Design Engineering School of Delft University of Technology(Netherlands). Delft Design Guide: Design strategies and methods[M]. Ni Yuwei Translator.Wuhan: Huazhong University of Science and Technology Press, 2014, pp. 32 33

[2] Lv Weijing. Interactive Design Research Based on Action-oriented and Subconscious[J]. Art and Design. 2015, Vol. 12, pp. 96-98

[3] Su Wenyu, Zhang Rongqiang. Application Research on Household Product Design Based on Unconsciousness Behavior[J]. Furniture \& Interior Design. 2016, Vol. 8, pp. 26-27

[4] Li Yajin, Liu Zijian. The important role of subconsciousness in product design. Beauty\& Times, 2011, Vol. 6, pp. 121 123

[5] Guo Yan. Subconsciousness in product design. Journal of Zhengzhou University of Light Industry(Social Science) 2009, Vol. 6, pp. 11 13

[6] Zhang Qian. Art principle [M]. Beijing: Peking University Press, 2008. pp. 5 . 